\title{
CONTROL OF DRYING SHRINKAGE IN MAGNESIUM SILICATE HYDRATE (M-S-H) GEL MORTARS
}

\author{
Tingting Zhang*a,c ${ }^{\text {a,c }}$ Xiaomin Liang ${ }^{\mathrm{a}}$, Changming $\mathrm{Li}^{* \mathrm{a}}$, M. Lorin ${ }^{\mathrm{b}}$, Yanying $\mathrm{Li}^{\mathrm{c}}$, Luc J. Vandeperre ${ }^{\mathrm{b}}$, \\ Chris R. Cheeseman ${ }^{c}$ \\ ${ }^{a}$ Faculty of Infrastructure Engineering, Dalian University of Technology, Dalian, 116000, China \\ ${ }^{b}$ Department of Materials, Centre for Advanced Ceramics, Imperial College London, \\ London, SW7 2AZ, UK \\ ${ }^{c}$ Department of Civil and Environmental Engineering, Imperial College London, \\ London, SW7 2AZ, UK
}

\begin{abstract}
Magnesium silicate hydrate (M-S-H) gel can be formed by the reaction of $\mathrm{MgO}$ with amorphous silica in the presence of sodium hexametaphosphate (Na-HMP). Typical pastes contain $40 \% \mathrm{MgO}$ and $60 \% \mathrm{SF}$ and have a w/c ratio of 0.5 but these exhibit shrinkage cracking on drying. The shrinkage characteristics of M-S-H mortar samples containing different additions of sand have been studied by dilatometry. The drying shrinkage was found to decrease with increasing sand addition and to increase with increased water content and was $0.16 \%$ for mortars with $60 \mathrm{wt} . \%$ sand and a w/c ratio of 0.5 . A simple geometrical model based on particle packing is presented that explains the observed changes in drying shrinkage. The drying shrinkage of the hydration products with zero sand addition is estimated to be 7.3\% after 7 days of curing and the density of $\mathrm{M}-\mathrm{S}-\mathrm{H}$ gel is estimated for the first time at $1.73 \mathrm{~g} \cdot \mathrm{cm}^{-3}$.
\end{abstract}

Keywords: Dispersion (A); Hydration products (B); Shrinkage (C); $\mathrm{MgO}$ (D); Silica fume (D)

\section{Introduction}

Previous research has demonstrated that reacting magnesium oxide $(\mathrm{MgO})$ with silica fume $\left(\mathrm{SiO}_{2}\right)$ in the presence of sodium hexametaphosphate (Na-HMP) forms magnesium silicate hydrate gel (M-S-H) with high strength $[1,2]$. The $\mathrm{pH}$ of these cements is $\sim 10$ and this is significantly lower than that observed in Portland cement systems. This factor combined with the excellent flow properties of this binder means these M-S-H cements could be used in a range of applications where low alkalinity is desirable such as the immobilisation of heavy $\underline{\text { metals including } \mathrm{Zn}, \mathrm{Pb} \text { or } \mathrm{Al}}[1,2]$. 
There has been limited research to date on M-S-H gel based cements and the development of new applications requires understanding of the durability of the product. An important durability issue is dimensional stability on wet/dry cycling and in initial experiments cracks were observed when M-S-H pastes made from $40 \% \mathrm{MgO} / 60 \% \mathrm{SF}$ samples (1\% Na-HMP) with w/s ratio 0.5 were dried. This cracking is believed to result from water loss from the MS-H gel structure. Experiments to overcome the drying shrinkage cracking showed that, as in many other cement systems [3, 4], the addition of fine sand to produce mortar samples reduced the dimensional changes sufficiently to suppress cracking. This research aimed to characterise drying shrinkage in M-S-H mortars and determine the resulting optimum mortar composition.

\section{Experimental methods}

Commercially available $\mathrm{MgO}$ (MgO, MagChem 30, M.A.F. Magnesite B.V., The Netherlands), silica fume (SF, Elkem Materials Ltd, UK) and a silica sand (RH110, Sibelco, $\mathrm{UK},>98 \% \mathrm{SiO}_{2}$ and mean diameter $144 \mu \mathrm{m}$ ) were used in the preparation of all samples.

The characteristics of the raw materials are reported in Table 1. The mean particle size of as-received sand (AS) was $176 \mu \mathrm{m}$ and this was reduced to $51 \mu \mathrm{m}$ in milled sand (MS).

Previous work[5] has shown that blends of $40 \mathrm{wt} \% \mathrm{MgO}$ and $60 \mathrm{wt} \%$ silica fume react to produce pure M-S-H gel with the average formula:

$$
\mathrm{Mg}_{8} \mathrm{Si}_{8} \mathrm{O}_{20}(\mathrm{OH})_{8} \cdot\left(\mathrm{H}_{2} \mathrm{O}\right)_{12}
$$

This composition was selected for further study and a range of mortars with different sand contents and water to cement ratios (w/c) were prepared as given in Table 2 . In all cases $1 \%$ Na-HMP (Fisher Scientific, UK) was added as a dispersant as this significantly improves the rheology of the pastes[5] and the reaction between $\mathrm{MgO}$ and silica. Samples were cast in steel moulds $(10 \times 10 \times 60 \mathrm{~mm})$ and were removed after 1 or 2 days and allowed to cure in a closed box with excess water to minimize sample drying.

Drying shrinkage was determined after 1 or 2 days, depending on sample strength, and then after 5 to 7,14 and 21 days curing.

Samples $(10 \times 10 \times 20 \mathrm{~mm})$ were rapidly heating $\left(20{ }^{\circ} \mathrm{C} \cdot \mathrm{min}^{-1}\right)$ to $200{ }^{\circ} \mathrm{C}$ in a dilatometer (DIL 402C, Netzsch, Germany) with the sample length continuously monitored. The temperature was measured with a thermocouple placed $3 \mathrm{~mm}$ from the sample surface. The maximum temperature was chosen to coincide with the first water loss step found in earlier thermogravimetric analysis of M-S-H gel, as shown in Figure 1. This indicates that for such a 
high heating rate, loosely bound water only leaves the structure if the heating is continued to approximately $200{ }^{\circ} \mathrm{C}$. The weight loss observed indicates that 9 of the 12 water molecules in equation 1 are lost more readily than the remaining 3. A similar difference in water bonding is known to occur in hydrated sepiolite[5]:

$$
\mathrm{Mg}_{8} \mathrm{Si}_{12} \mathrm{O}_{30}(\mathrm{OH})_{4} \cdot\left(\mathrm{H}_{2} \mathrm{O}\right)_{12}
$$

which forms an intermediate structure containing 4 waters during drying.

The composition of the mixes prepared is given in Table 3. The sand content was increased from 50 to 75 wt.\% and 2 wt.\% of Na-HMP was used to make workable pastes. The density, porosity, water absorption and compressive strength of each mix was determined to characterise M-S-H gel systems containing different sand contents.

For the determination of the density, first the samples were saturated with water by submerging in water for $24 \mathrm{~h}$ and measuring the mass in air after carefully removing the surface water (water saturated sample). Then the mass of the water saturated sample was measured while it was submerged in water (water immersed sample). Finally the sample was dried at $105{ }^{\circ} \mathrm{C}$ and its dry mass in air determined. The density was then calculated using equation 3:

$$
\rho\left(\mathrm{g} \cdot \mathrm{cm}^{-3}\right)=\frac{m_{\mathrm{dry}}}{m_{\mathrm{sat}}-m_{\mathrm{imm}}} \times \rho_{\mathrm{H}_{2} \mathrm{O}}
$$

where $\rho_{\mathrm{H}_{2} \mathrm{O}} \approx 1.0 \mathrm{~g} / \mathrm{cm}^{3}$ at $10^{\circ} \mathrm{C}$ under atmospheric pressure [6].

The water accessible porosity of mortar samples was determined using:

$$
\text { Porosity }=\frac{\text { Volume of voids }}{\text { Volume of sample }}=\frac{m_{\mathrm{sat}}-m_{\mathrm{dry}}}{m_{\mathrm{imm}}} \times 100 \%
$$

The water absorption was determined from the increased mass of oven-dried mortar samples caused by permeation of water into the pores when samples were immersed in water for 24 hours using:

$$
\text { Water Absorption (\%) }=\frac{m_{\text {sat }}-m_{\mathrm{dry}}}{m_{\mathrm{dry}}} \times 100 \%
$$

The unconfined compressive strength of samples measuring $10 \times 10 \times 10 \mathrm{~mm}$ was determined using a Zwick/Roell Z010 load frame (Zwick/Roell, Germany) with a $10 \mathrm{kN}$ load cell. The loading rate used was $300 \mathrm{kPa} / \mathrm{s}$ and the load causing sample blocks to fracture was recorded. At least 5 specimens for each composition were tested to allow calculation of mean and standard deviation for compressive strength data.

\section{Results}


Figure 2 illustrates how the length of the samples changes during heating. Although the temperature was programmed to increase to $200{ }^{\circ} \mathrm{C}$, a small overshoot occurred leading to samples being exposed to $230{ }^{\circ} \mathrm{C}$. The samples start shrinking at about $85^{\circ} \mathrm{C}$ and that the shrinkage appears to occur in 2 steps. The first step is complete by $165{ }^{\circ} \mathrm{C}$ and a further step in shrinkage occurs above $200{ }^{\circ} \mathrm{C}$.

The total shrinkage of samples with a w/s ratio of 0.5 are shown in Figure $3 \mathrm{a}$ as a function of curing age. Although there is some variability, the differences between mortars with different sand content are larger than the differences with age. Therefore the average of the measurements over the different ages can be plotted as a function of the volume fraction of sand and this is shown in Figure 3b. In line with work on other mortars and concretes, adding sand, which itself will not shrink when the mortar is dried, reduces the drying shrinkage. Mortars with more water have increased shrinkage for the same volume fraction of added sand. The drying shrinkage of M-S-H paste samples with no sand addition is high compared to Portland cement based mortars and concrete[7-9].

Figure $4 \mathrm{a}$ shows the density of mortar samples of the second series that had a large sand addition. Quartz has a higher density than the binder phases and therefore the density of the products increases with sand addition. Figure $4 \mathrm{~b}$ shows the variation of porosity with sand content and Figure $4 \mathrm{c}$ shows the variation of water adsorption with sand content. The latter two parameters decrease with sand addition as the water to cement ratio is constant and hence adding more sand increases the volume fraction of solids present.

The compressive strength variation with sand content is shown in Figure 5. The data is somewhat surprising as the compressive strength decreases when porosity decreases, whereas normally the reverse is observed.

\section{Discussion}

The mass loss steps in the TGA trace indicate that the mass loss during heating of M-S-H gel to high temperature occurs roughly in three steps with stoichiometries given by:

\section{(1)} 1 32 
The first shrinkage step in the dilatometry occurs largely over the temperature range of the first mass loss. It is clear also that above $200{ }^{\circ} \mathrm{C}$ a further shrinkage step starts, which could therefore be the result of the loss of the final three waters. However, the latter step is expected to only complete by $450{ }^{\circ} \mathrm{C}$ and since the temperature never exceeded $230{ }^{\circ} \mathrm{C}$, the second shrinkage step was probably not measured in its entirety.

The higher shrinkage observed for mortars with high water to cement ratio is in agreement with the normal behaviour of cement mortars and concrete[10], even though some authors have reported that the w/c ratio is less important than often stated[11]. The observation that adding sand reduces shrinkage is expected as the sand is not involved in the hydration reactions and relative to the gel its drying shrinkage is negligible and of the order of $10^{-4}$ for quartz sand compared to $\sim 10^{-2}$ for the gel $[12,13]$. and aggregate can be taken as 0.12 :

$$
\varepsilon_{c}=\varepsilon_{p} \cdot \frac{\left(1-V_{a}\right)}{2} \cdot\left[\frac{1}{1-V_{a}+0.58 m V_{a}}+1-V_{a}+\frac{1.72}{m} V_{a}\right]
$$

Where $\mathrm{V}_{\mathrm{a}}$ is the volume fraction of aggregates and $\mathrm{m}$ is the ratio of the elastic modulus of the it is difficult to apply the expression directly, but as illustrated in Figure $3 \mathrm{~b}$ a good fit to the shrinkage data can be obtained assuming a modulus ratio of 10 .

However, while such composite models using a non-shrinking particle inside a homogeneously shrinking matrix might be useful for mature pastes, the real microstructure when the hydration reactions have not proceeded very far are very different as they consist of solid particles of sand, $\mathrm{MgO}$ and silica fume, bridged by the first hydration products as no homogeneous matrix has formed. Moreover, the fact that the shrinkage remains more or less constant over 28 days, as shown in Figure 3b, must mean that the initial structure of the paste retains an influence over the shrinkage even as the mortar becomes fairly mature. 
Furthermore, plotting the shrinkage as a function of the volume fraction of all solids, $v_{\mathrm{s}}$, rather than the volume fraction of sand, as shown in Figure 6 brings the results for both water contents to a single trend, which shows that this is the correct normalising factor. Extrapolation of the results now shows that the shrinkage will reduce to zero when the volume fraction of solids in the paste is about 0.77 .

In terms of particle packing, a volume fraction of 0.77 is high, leading to the conclusion that the shrinkage tends to zero when the solid particles in the paste are touching. This conclusion is in line with the observations from the second series of mortars. As the sand content increased above $68.8 \mathrm{wt} \%$ (volume fraction solids 0.74 ), the data in Figure 4 starts to deviate from expectation because there is simply too much solid in the paste.

It follows that the magnitude of the shrinkage could scale with a characteristic distance between the solid particles in the paste. Such assumption is entirely consistent with the direct observations made using the digital image correlation method of drying shrinkage in concrete. Indeed their observations suggested that the drying shrinkage is due to excess paste between the aggregates[18], an idea originally proposed by Kennedy[19]. To investigate this assumption, an idealised description of the paste structure was considered by modelling the paste as a regular packing of equal size particles. While such a description is highly idealized, it has previously been used to successfully explain variations in the setting time[20] and drying shrinkage[21] of cement pastes and the mechanical properties of porous ceramics[22]. Noting that the strain tends to zero for a volume fraction of solids of 0.77 , which is not too far from 0.68 , the packing fraction obtained when particles of equal size are in contact in a body cubic centred lattice (bcc), this type of packing was used. It is assumed further that when the volume fraction of solids decreases, the particles will retain the same average arrangement, i.e only the inter-particle distances become larger. This can be achieved through increasing the size of the unit cell, $a$, to give a volume fraction of solid equal to the volume fraction of solids in the paste. As shown in Figure 7 each bcc unit cell contains just 2 particles and hence the relationship between solid volume fraction, $v_{\mathrm{s}}$, particle radius, $r$, and unit cell parameter, $a$, for bec crystals is:

$$
v_{s}=\frac{2 \cdot \frac{4 \pi}{3} r^{3}}{a^{3}}
$$

Rearranging this expression yields a characteristic ratio of particle radius, $r$, and unit cell parameter, $a$, as a function of the volume fraction of solids in the paste: 


$$
\frac{r}{a}=\sqrt[3]{\frac{3 v_{s}}{8 \pi}}
$$

As illustrated in Figure 7, which also shows scaled drawings of the packing in some of the mortars, the particles are not touching but are close to touching in the mortar with $60 \mathrm{wt} \%$ sand and a water to cement ratio of 0.5 , which showed the lowest shrinkage after drying.

During curing the pastes retain the shape of the mould and did not exhibit bleeding. Therefore, solidification of the pastes during set occurs because the hydration products form solid bridges between the particles, which themselves remain largely at the same positions they had in the unset mortar. In Figure 7, only the linkages which cover the shortest distances between solid particles are shown. In a bcc arrangement, these are along the body diagonal of the cube. The total length of the body diagonal is $\sqrt{3} a$ and a distance $4 \cdot r$ of this length consists of solid particles. Hence, the length bridged by hydration products is $\sqrt{3} a-4 r$. It is assumed further that during drying the solid particles will not shrink and that the hydration products shrink by a fixed amount per unit length, $\varepsilon_{s h}$. Since the linkages along the body diagonal contain the lowest amount of hydration product per unit length, this limits the overall shrinkage of the structure, which is therefore given by:

$$
\frac{\Delta l}{l}=\frac{(\sqrt{3} a-4 r) \cdot \varepsilon_{s h}}{\sqrt{3} a}
$$

Eliminating $r / a$ from this expression using equation 10 yields the following relationship between volume fraction solids and drying shrinkage:

$$
\frac{\Delta l}{l}=\left(1-\frac{4}{\sqrt{3}} \sqrt[3]{\frac{3 v_{s}}{8 \pi}}\right) \cdot \varepsilon_{s h}
$$

The maximum volume fraction of solids in a bcc arrangement is:

$$
v_{s, \max }=\frac{\sqrt{3} \pi}{8}
$$

Therefore equation 13 can be rewritten as:

$$
\frac{\Delta l}{l}=\left(1-\left(\frac{v_{s}}{v_{s, \max }}\right)^{1 / 3}\right) \varepsilon_{s h}
$$

Repeating the same calculation for primitive cubic or face centred cubic leads to the same result, so that equation 15 can be generalised with $\mathrm{v}_{\mathrm{s}, \max }$, the volume fraction where the particles touch in the slurry and shrinkage ends for any distribution of particles. 
The line in Figure 6 is a least square fit of this simple geometric interpretation to the experimentally observed shrinkages. The fit suggest that the maximum volume fraction of solids is 0.77 and that M-S-H gel forming in a solid free paste would have a drying shrinkage of $6.1 \%$. Note that the latter is effectively the drying shrinkage of M-S-H gel made at infinite dilution with water and not the drying shrinkage of the paste without sand, which clearly is much lower at $1.5 \%$ for a w/c of 0.8 and $1.3 \%$ for a w/c of 0.5 .

To some extent this good agreement is surprising as the cement particles will react to create the hydration products and hence slowly disappear from the solid particle network. However, when Portland cement hydrates, a distinction is often made between lower and higher density regions in the hydration products, with the early gel formation being lower density than the product formed at later stages[23]. Garci et al., [21] also attribute the shrinkage to water removal from the capillary pores and from the lower density hydrated phase, whereas the high density phases forming on the unhydrated cement particles and the unhydrated cement particles themselves do not shrink during drying. Hence, the continued scaling of the shrinkage with initial packing density observed here suggest that the brucite and M-S-H gel forming early between the solid particles also create a low density network, whereas the product formed during later hydration is much denser and does not contribute much to the drying shrinkage so that the correlation with initial volume fraction of solids is retained.

For the second series of mortars, the measured densities, porosities and water adsorption were compared with a simple calculation to predict these properties. Assuming a cement paste is just the sum of its components, the mass and volume of the paste are easily found:

$$
\begin{aligned}
& M=\sum_{i} m_{i} \\
& V=\sum_{i} \frac{m_{i}}{\rho_{i}}
\end{aligned}
$$

from the masses, $m_{\mathrm{i}}$ of each component $i$ added to the formulation and the densities of the components, $\rho_{\mathrm{i}}$, see Table 4. Assuming equation 1 describes the reaction stoichiometry accurately, it is straightforward to define an extent of hydration $\alpha$. If no hydration reactions have taken place then $\alpha=0$ while if the maximum amount of $M-S-H$ gel has formed $\alpha=1$. It is then straightforward for any assumed value of $\alpha$ to calculate the amount of water, $\mathrm{MgO}$ and silica fume that remain as well as the amount of M-S-H gel that has formed. Because the density was measured after drying, the expression for the overall density is: 


$$
\rho=\frac{M-m_{H_{2} O}^{\alpha}}{V}
$$

253

254

where $m_{\mathrm{H}_{2} \mathrm{O}}^{\alpha}$ is the remaining free water after the M-S-H forming reaction has been allowed to occur to an extent $\alpha$.

The porosity or pore volume fraction, $P$, is given by:

$$
P=1-\frac{V_{s}^{\alpha}}{V}
$$

where $V_{s}^{\alpha}$ is the volume of solids after the reaction has proceeded to an extent $\alpha$. Finally an expression for the water adsorption is:

$$
W A=\frac{P \cdot V \cdot \rho_{\mathrm{H}_{2} \mathrm{O}}}{M-m_{\mathrm{H}_{2} \mathrm{O}}^{\alpha}}
$$

These relations were used to calculate the variation of density, porosity and water adsorption for different assumed values of the extent of reaction, giving rise to the different lines in Figure 4. The best fit to the water adsorption and density data was found for $\alpha=0.33$ and a density for the M-S-H gel of $1.73 \mathrm{~g} . \mathrm{cm}^{-3}$. Previous work has shown that full reaction to form M-S-H requires at least 90 days in similar mortars and hence an estimate for $\alpha$ of 0.33 is reasonable. The density estimate for M-S-H is somewhat lower than that of similar crystalline phases such as chrisotyle $\left(2.53 \mathrm{~g} . \mathrm{cm}^{-3}\right)$, sepiolite $\left(2.25 \mathrm{~g} . \mathrm{cm}^{-3}\right)$ and serpentine $\left(2.55 \mathrm{~g} . \mathrm{cm}^{-3}\right)$, as could be expected for an amorphous product, suggesting the fits to the data are quite accurate[24]. The advantage is that this means that the porosity in mortars can easily be predicted or designed.

The evolution of compressive strength of the mortars with porosity is a-typical as the strength increases when the pore volume fraction gets larger. However, a second parameter determining strength is the ratio of the volume of hydration products to the volume of aggregate that needs binding. As shown in Figure 8, this ratio becomes quite small for small values of $\alpha$ and large amounts of sand. For mixtures approaching $80 \mathrm{wt} . \%$ sand, the volume of the hydration products is less than $10 \%$ of the volume of the aggregate it needs to bind, which means that linkages are relatively limited and hence the strength reduces. It would be interesting to study these mortars for longer times as the strengths could potentially rise substantially.

\section{Conclusions}


Drying shrinkage of mortars made by blending $\mathrm{MgO}$, silica fume, $\mathrm{Na}-\mathrm{HMP}$, sand and water was higher when the water content was higher and/or the sand content lower, which is entirely consistent with observations for mortars based on Portland cement.

The magnitude of the drying shrinkage can be described both by a general composite model considering non-shrinking particles in a shrinking matrix as well as by a characteristic minimum inter-particle distance in the paste. Therefore the shrinkage is governed by the ratio of the volume fraction of solids in the paste and the volume fraction of solids when a touching solid particle network forms. Moreover, the overall drying shrinkage of aged samples is limited to the shrinkage of the hydration products between the original particles.

For the M-S-H mortars studied here, extrapolating the results to zero solids in the paste suggests that the drying shrinkage of an M-S-H gel formed at infinite dilution amounts to $6.12 \%$. The drying shrinkage of pure M-S-H pastes with lower water contents is much lower at $1.5 \%$ for $\mathrm{w} / \mathrm{c}=0.8$ and $1.3 \%$ for $\mathrm{w} / \mathrm{c}=0.5$ and can be reduced further through the addition of sand.

The density of M-S-H gel has been estimated for the first time at $1.73 \mathrm{~g} . \mathrm{cm}^{-3}$. Predicting porosity and water adsorption in M-S-H gel based systems is easily achieved, allowing for the design of these properties.

\section{Acknowledgements}

This work was funded by the UK Engineering and Physical Sciences Research Council (EPSRC) through grant number EP/F055412/1, the National Natural Science Foundation of China (Grant No. 51408096) and Dalian Construction Technology program (201309).

\section{References}

1. Tingting Zhang, L.J.V., Christopher R. Cheeseman, Magnesium-silicate-hydrate cements for encapsulating problematic aluminium containing wastes. Journal of Sustainable CementBased Materials, 2012. 1: p. 34-45.

2. Quina, M.J., J.C.M. Bordado and R.M. Quinta-Ferreira, The influence of $\mathrm{pH}$ on the leaching behaviour of inorganic components from municipal solid waste APC residues. Waste Management, 2009. 29: p. 2483-2493.

3. Celen, I., et al., Using a chemical equilibrium model to predict amendments required to precipitate phosphorus as struvite in liquid swine manure. Water Research, 2007. 41(8): p. 1689-1696.

4. Carsten Künzel, L.V., Shane Donatello, Aldo R. Boccaccini, C.R. Cheeseman and P. Brown, Ambient Temperature Drying Shrinkage and Cracking in Metakaolin - Based Geopolymers. Journal of the American Ceramic Society 2012. 95(10): p. 3270-3277. 
5. Tingting Zhang, L.J.V., Christopher R. Cheeseman, Formation of magnesium silicate hydrate (M-S-H) cement pastes using sodium hexametaphosphate. Cement \& Concrete Research, 2014. 65(11): p. 8-14.

6. Weast, R.C., Handbook of Chemistry and Physics, $53^{\text {rd }}$ Edition. 1972, Cleveland: CRC Press.

7. Cebeci, O.Z., S.I. Al-Noury, and W.H. Mirza, Strength and drying shrinkage of masonry mortars in various temperature humidity environments. Cement and Concrete Research, 1989. 19: p. 53-62.

8. Toledo, R.D., et al., Free, restrained and drying shrinkage of cement mortar composites reinforced with vegetable fibres. Cement \& Concrete Composites, 2005. 27(5): p. 537-546.

9. Videla, C. and C. Aguilar, An updated look at drying shrinkage of Portland and blended Portland cement concretes. Magazine of Concrete Research, 2006. 58(7): p. 459-476.

10. Neville, A.M., Properties of Concrete, 4th Edition. 1995, London: Pitman Publishing. 687.

11. Bissonnette, B., P. Pierre, and M. Pigeon, Influence of key parameters on drying shrinkage of cementitious materials. Cement and Concrete Research, 1999. 29: p. 1655-1662.

12. Zhang, W., M. Zakaria and Y. Hama, Influence of aggregate materials characteristics on the drying shrinkage properties of mortar and concrete. Construction and Building Materials, 2013. 49: p. 500-510.

13. Igarashi, G., I. Maruyama, Y. Nishioka and H. Yoshida Influence of mineral composition of siliceous rock on its volume change. Construction and Building Materials, 2015. 94: p. 701709.

14. Bazant, Z.P., Prediction of concrete creep and shrinkage: past, present and future. Nuclear Engineering and Design, 2001. 203: p. 27-38.

15. Gardner, N.J., Comparison of prediction provisions for drying shrinkage and creep of normalstrength concretes. Canadian Journal of Civil Engineering, 2004. 31: p. 767-775.

16. Grassl, P., H. Wong, and N. Buenfeld, Influence of aggregate size and volume fraction on shrinkage induced micro-cracking of concrete and mortar. Cement and concrete research, 2010. 40(1): p. 85-93.

17. Hansen, W., Constitutive Model for Predicting Ultimate Drying Shrinkage of Concrete. Journal of the American Ceramic Society, 1987. 70(5): p. 329-332.

18. Maruyama, I.a.H.S., Strain and crack distribution in concrete during drying. Materials and Structures, 2014. 47(3): p. 517-532.

19. CT, K., The design of concrete mixes. Proc Am Concr Inst, 1940. 36: p. 373-400.

20. Vandeperre, L.J., M. Liska, and A. Al-Tabbaa. A comparison between two types of pfa in the performance of blends of MgO, PC and pfa. in Ashtech 2006. 2006. Birmingham: United Kingdom Quality Ash Assocation.

21. Garci Juenger, M.C. and H.M. Jennings, Examining the relationship between the microstructure of calcium silicate hydrate and drying shrinkage of cement pastes. Cement and Concrete Research, 2002. 32: p. 289-296.

22. Vandeperre, L.J., J. Wang, and W.J. Clegg, Effects of porosity on the fracture energy of brittle materials. Philosophical Magazine, 2005. 84(34): p. 3689-3704.

23. Mindess, S., J.F. Young, and D. Darwin, Concrete. second ed. 2003, Upper Saddle River: Prentice Hall. 644.

24. Tingting Zhang, L.J.V.a.C.R.C., Formation of magnesium silicate hydrate $(M-S-H)$ cement pastes using sodium hexametaphosphate. Cement and Concrete Research, 2014. 65(1): p. 814. 


\section{Table 1}

Characteristics of the raw materials.

\begin{tabular}{ccc}
\hline $\begin{array}{c}\text { Composition } \\
(\text { wt. })\end{array}$ & $\mathrm{MgO}$ & Silica fume \\
$\mathrm{SiO}_{2}$ & 0.35 & $>97.5$ \\
$\mathrm{Al}_{2} \mathrm{O}_{3}$ & 0.1 & $<0.7$ \\
$\mathrm{Fe}_{2} \mathrm{O}_{3}$ & 0.15 & $<0.3$ \\
$\mathrm{CaO}$ & 0.8 & $<0.3$ \\
$\mathrm{P}_{2} \mathrm{O}_{5}$ & $(\mathrm{n} / \mathrm{a})$ & $<0.1$ \\
$\mathrm{MgO}$ & 98.2 & $<0.5$ \\
$\mathrm{~K}_{2} \mathrm{O}$ & $(\mathrm{n} / \mathrm{a})$ & $<0.6$ \\
$\mathrm{Na}_{2} \mathrm{O}$ & $(\mathrm{n} / \mathrm{a})$ & $<0.3$ \\
$\mathrm{SO}_{3}$ & 0.05 & $<0.4$ \\
\hline Specific gravity $\left(\mathrm{g} . \mathrm{cm}^{-3}\right)$ & 3.23 & 1.94 \\
Mean particle size $(\mu \mathrm{m})$ & 5 & $\mathrm{NA}$ \\
BET surface area $\left(\mathrm{m}^{2} \cdot \mathrm{g}^{-1}\right)$ & 25 & 21.4 \\
\hline
\end{tabular}

Table 2

Mortar formulations ( $\mathrm{w} / \mathrm{c}=$ water to cement ratio, $\mathrm{SF}=$ silica fume).

\begin{tabular}{cccccccc}
\hline & $\begin{array}{c}\text { Cement } \\
\text { MgO/SF }\end{array}$ & Sand & w/c & MgO & SF & sand & water \\
No. & wt.\% & wt.\% & ratio & $\mathrm{g}$ & $\mathrm{g}$ & $\mathrm{g}$ & $\mathrm{g}$ \\
\hline 1 & 100 & 0 & 0.5 & 40 & 60 & 0 & 50 \\
2 & 80 & 20 & 0.5 & 40 & 60 & 25 & 50 \\
3 & 60 & 40 & 0.5 & 40 & 60 & 67 & 50 \\
4 & 40 & 60 & 0.5 & 40 & 60 & 150 & 50 \\
5 & 100 & 0 & 0.8 & 40 & 60 & 0 & 80 \\
6 & 80 & 20 & 0.8 & 40 & 60 & 25 & 80 \\
7 & 60 & 40 & 0.8 & 40 & 60 & 67 & 80 \\
8 & 40 & 60 & 0.8 & 40 & 60 & 150 & 80 \\
\hline
\end{tabular}




\section{Table 3}

Composition of mixes for samples in the study on effect of changing the sand content.

\begin{tabular}{ccccc}
\hline $\begin{array}{c}\text { Sample } \\
\text { No. }\end{array}$ & $\begin{array}{c}\text { Cement } \\
\text { MgO: SF: Na-HMP } \\
\text { wt.\% }\end{array}$ & $\begin{array}{c}\text { w/c } \\
\text { ratio }\end{array}$ & $\begin{array}{c}\text { Sand } \\
\mathrm{g}\end{array}$ & $\begin{array}{c}\text { Sand } \\
\text { content } \\
\text { wt.\% }\end{array}$ \\
\hline E1 & $40: 60: 2$ & 0.6 & 50 & 50.0 \\
E2 & $40: 60: 2$ & 0.6 & 60 & 54.5 \\
E3 & $40: 60: 2$ & 0.6 & 70 & 58.3 \\
E4 & $40: 60: 2$ & 0.6 & 80 & 61.5 \\
E5 & $40: 60: 2$ & 0.6 & 85 & 63.0 \\
E6 & $40: 60: 2$ & 0.6 & 90 & 64.3 \\
E7 & $40: 60: 2$ & 0.6 & 100 & 66.7 \\
E8 & $40: 60: 2$ & 0.6 & 110 & 68.8 \\
E9 & $40: 60: 2$ & 0.6 & 120 & 70.6 \\
E10 & $40: 60: 2$ & 0.6 & 130 & 72.2 \\
E11 & $40: 60: 2$ & 0.6 & 140 & 73.7 \\
E12 & $40: 60: 2$ & 0.6 & 150 & 75.0 \\
\hline
\end{tabular}

\section{Table 4}

Densities and molar masses for the cement components and the sole hydration product considered.

\begin{tabular}{lc}
\hline Name & $\begin{array}{c}\text { Density } \\
\mathrm{g} \cdot \mathrm{cm}^{-3}\end{array}$ \\
\hline $\mathrm{MgO}$ & 3.58 \\
Silica fume & 2.2 \\
Quartz sand & 2.65 \\
M-S-H gel & 1.73 \\
\hline
\end{tabular}




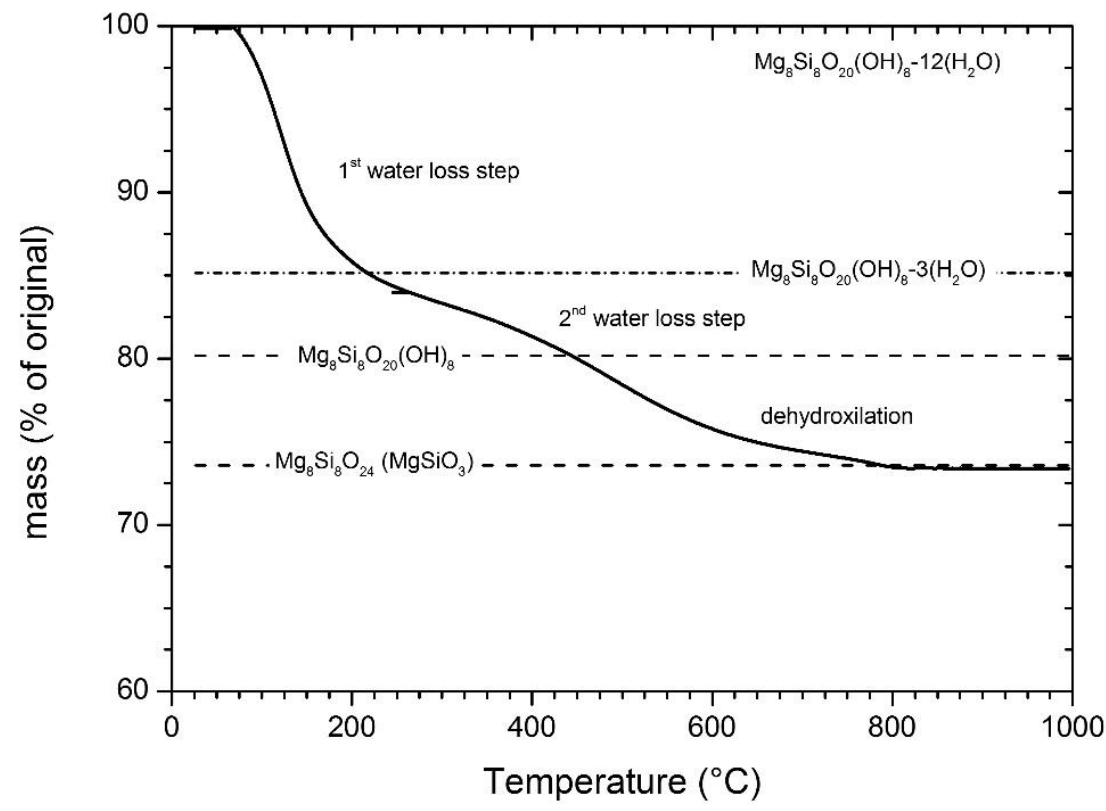

Fig. 1. Thermogravimetric analysis using a heating rate of $10^{\circ} \mathrm{C} \cdot \mathrm{min}^{-1}$ of a cement sample with no sand addition and a w/c ratio of 0.8 after 285 days of curing and 24 hours drying at $105^{\circ} \mathrm{C}$. X-ray diffraction shows only the presence of M-S-H gel in such samples.

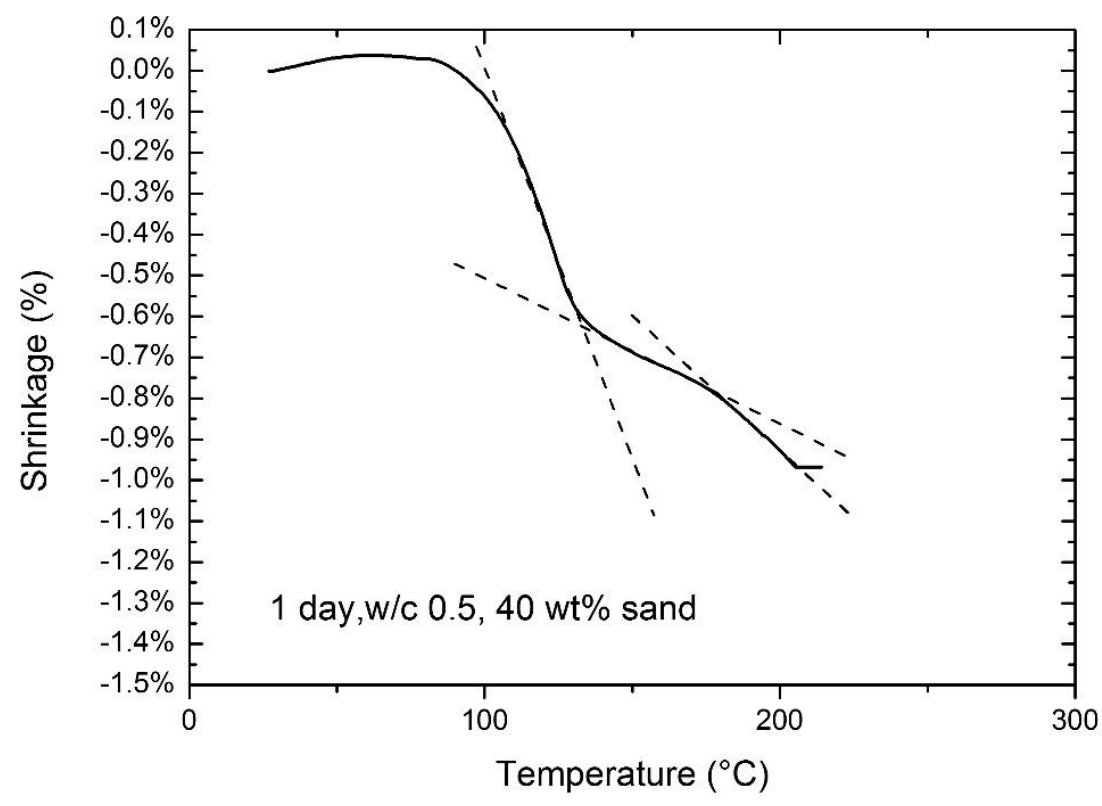

Fig. 2. Examples of the changes in length observed during heating for a M-S-H mortar with $40 \mathrm{wt} \%$ sand and a water to cement ratio of 0.5 after 1 day of curing. 


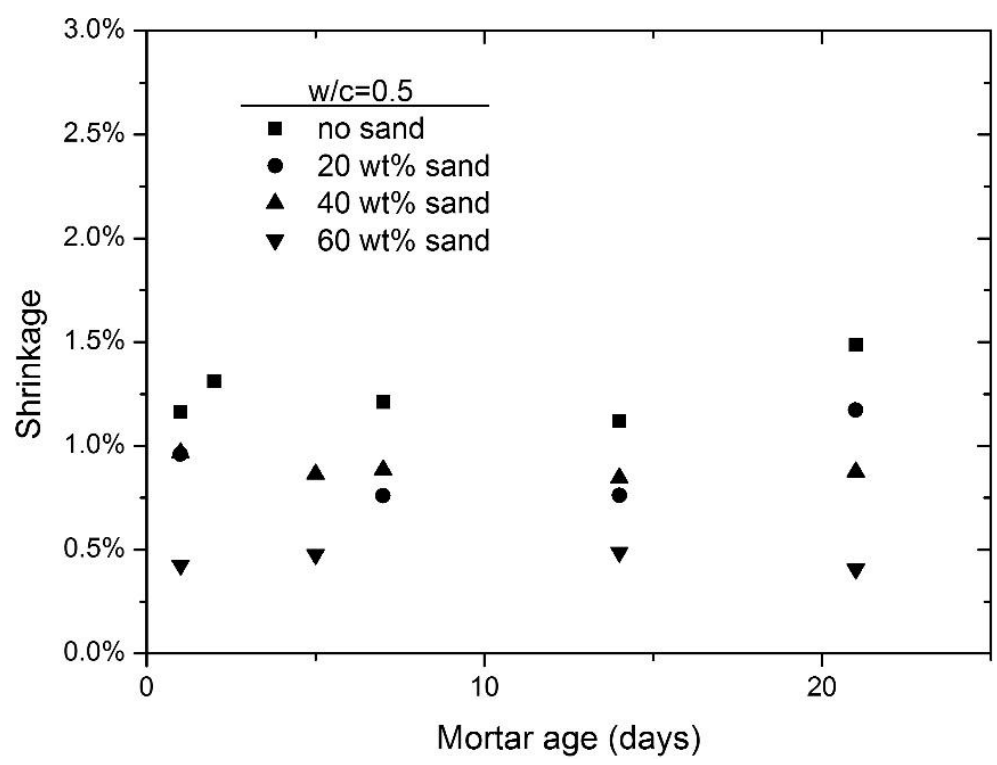

(a)

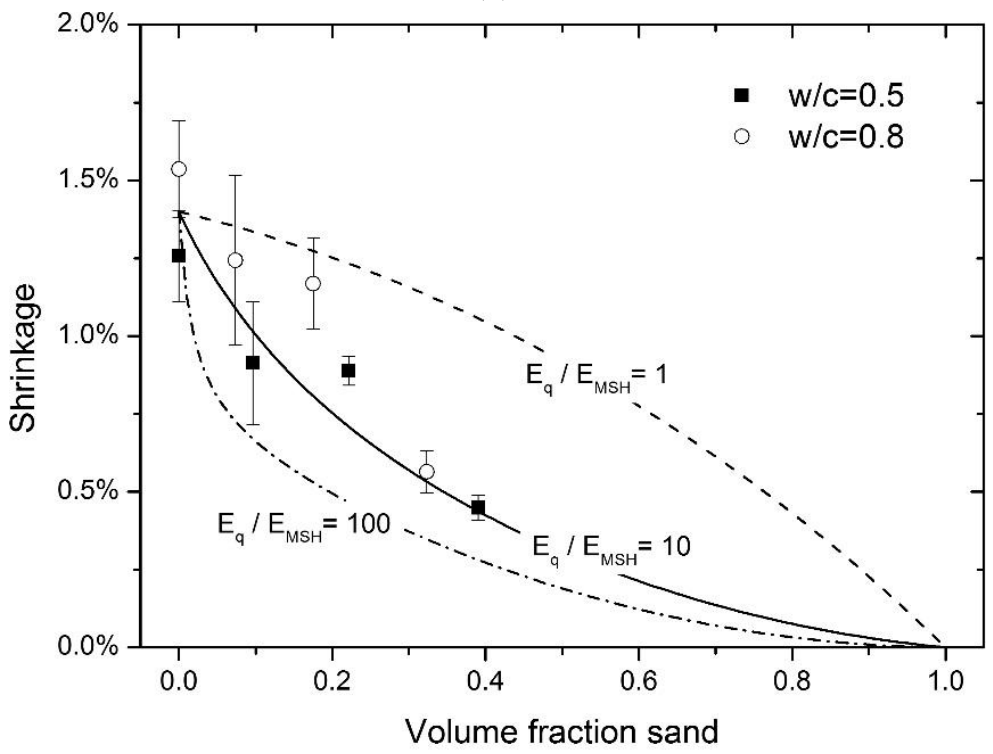

(b)

Fig.3.(a) Drying shrinkage versus age for 1:1 magnesium to silica fume molar ratio mortars with $w / c=0.5$ and different sand contents. Data points represent single measurements. (b) Average shrinkage over the different ages as a function of the volume fraction sand for mortars with $\mathrm{w} / \mathrm{c}=0.5$ and $\mathrm{w} / \mathrm{c}=0.8$. The lines are calculated shrinkage based on Hansen's model for different assumed ratios of the elastic modulus of quartz, $E_{\mathrm{q}}$, to the elastic modulus of M-S-H gel, $\mathrm{E}_{\mathrm{MSH}}$. 

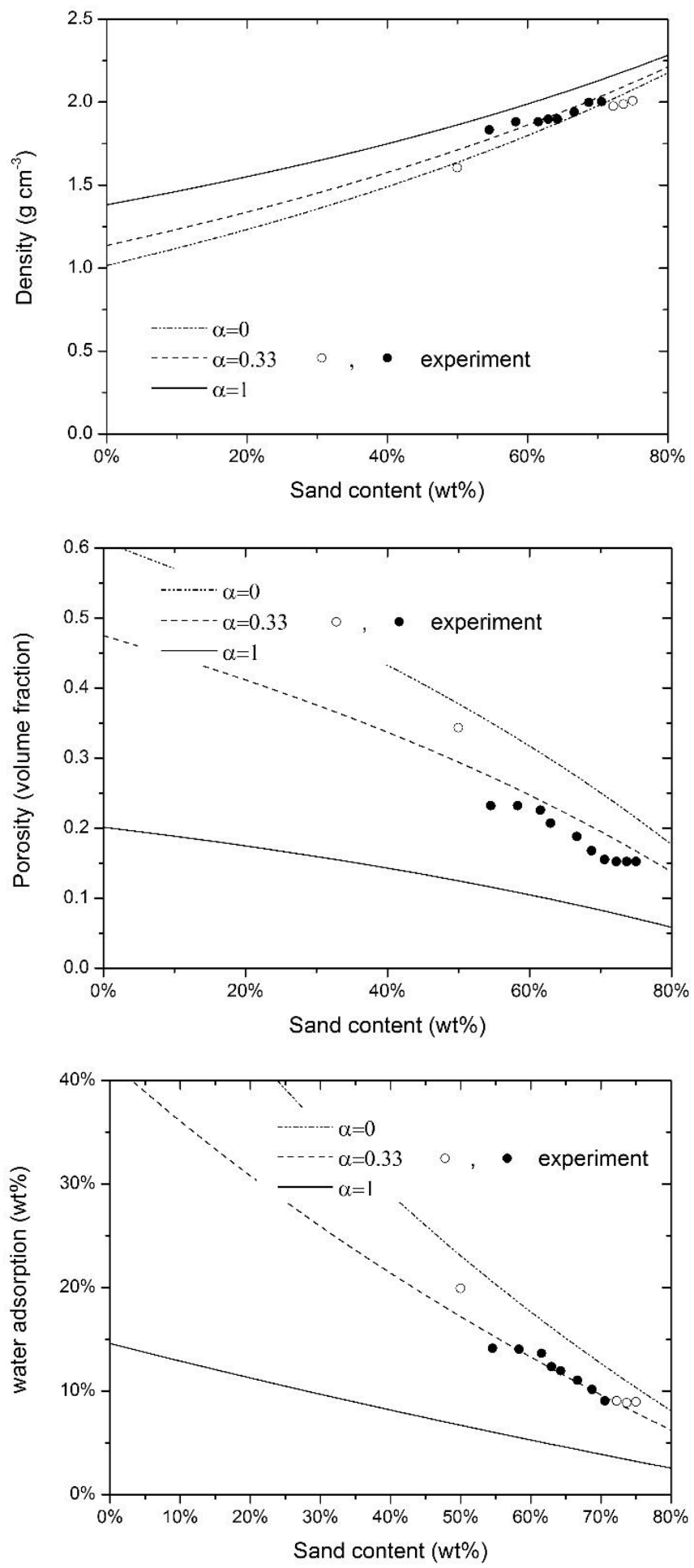

Fig. 4. Density, porosity and water adsorption as a function of the sand content for a magnesium silicate hydrate cement with $4 \mathrm{~g} \mathrm{MgO} / 6 \mathrm{~g}$ silica fume and a w/c ratio of 0.6. The filled circles are the experimental points measured at an age of 28 days. The lines were calculated assuming different extents of reaction, between $\mathrm{MgO}$, silica fume and water according to $8 \mathrm{MgO}+8 \mathrm{SiO}_{2}+16 \mathrm{H}_{2} \mathrm{O} \leftrightarrow \mathrm{Mg}_{8} \mathrm{Si}_{8} \mathrm{O}_{20}(\mathrm{OH})_{8} \cdot\left(\mathrm{H}_{2} \mathrm{O}\right)_{12}$ 


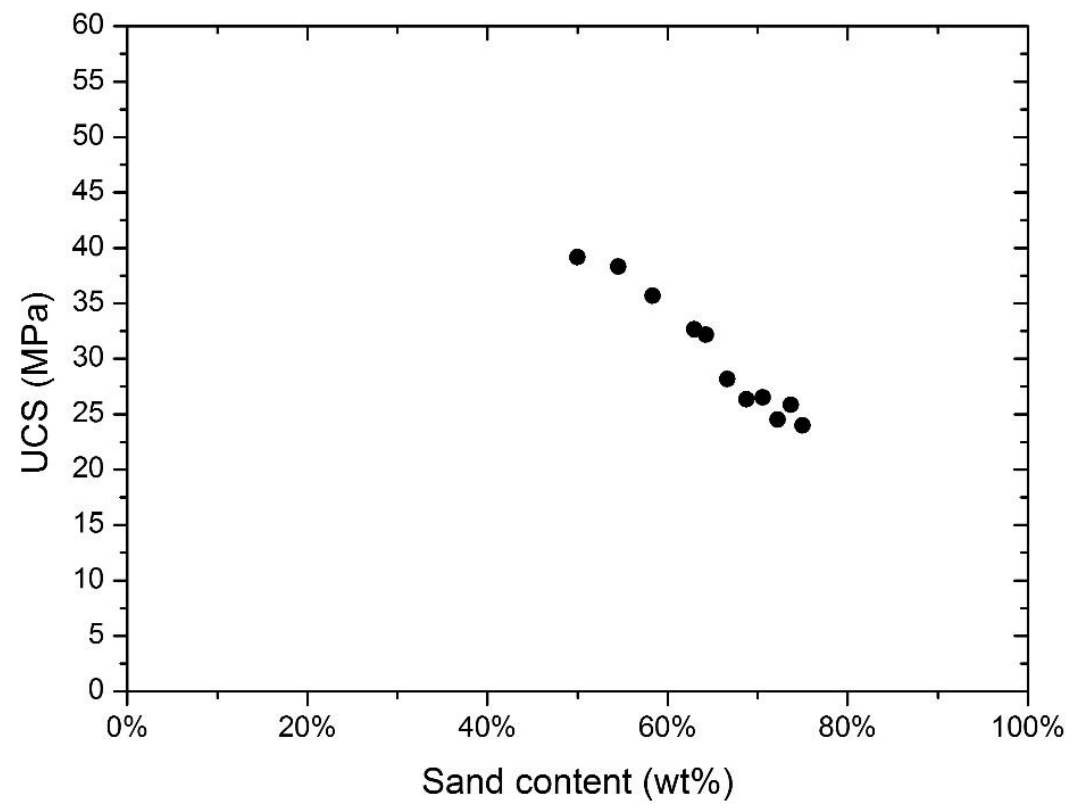

Fig. 5. Unconfined compressive strength (UCS) of samples as a function of sand content.

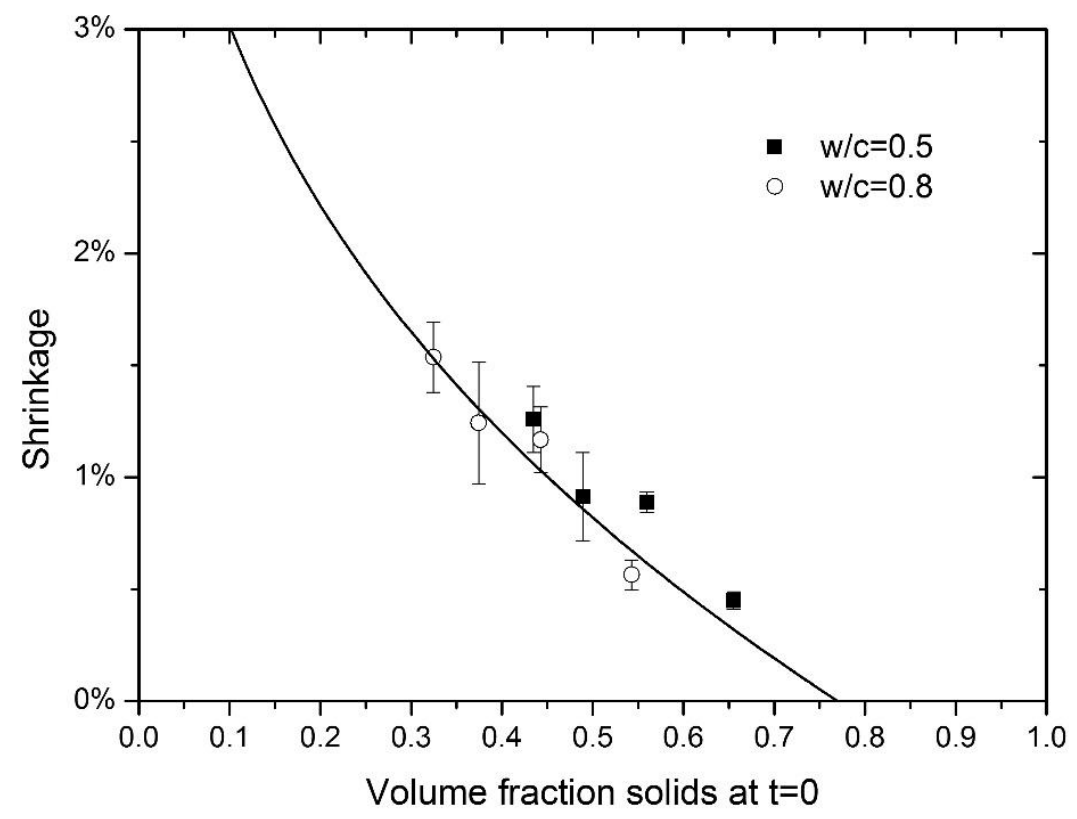

Fig. 6. Shrinkage as a function of the volume fraction of solids in the mortar at the time of production for mortars with $w / c=0.5$ and mortars with $w / c=0.8$. The line is calculated using the concept of a maximum volume fraction solids which leads to a network of touching particles as developed in the discussion. 


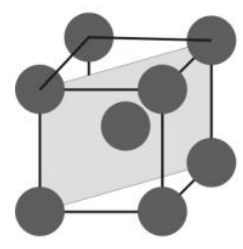

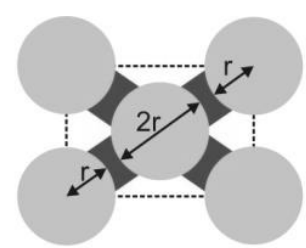

w/s $0.5,0 \%$ sand

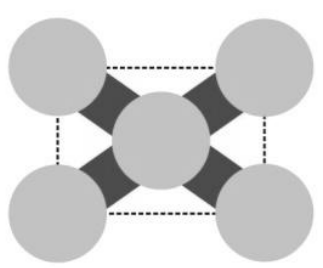

w/s $0.8,0 \%$ sand

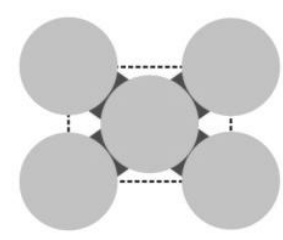

w/s $0.5,60 \%$ sand

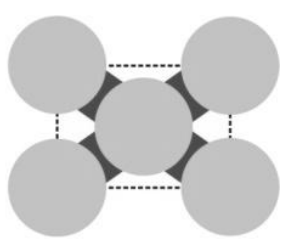

w/s $0.8,60 \%$ sand

Fig. 7. A geometrical model for the spacing between the solid particles in the paste and the linkages that form during curing based on a body centred cubic crystal structure (left). A scaled view on the (110) type planes in the structure is shown for different sand and water contents. The shortest distance between solid particles is along the diagonal in this plane and it can be thought to consist of solid particles over a length $4 \mathrm{r}$ and hydration product linkages over a length $3^{1 / 2} \mathrm{a}-4 \mathrm{r}$.

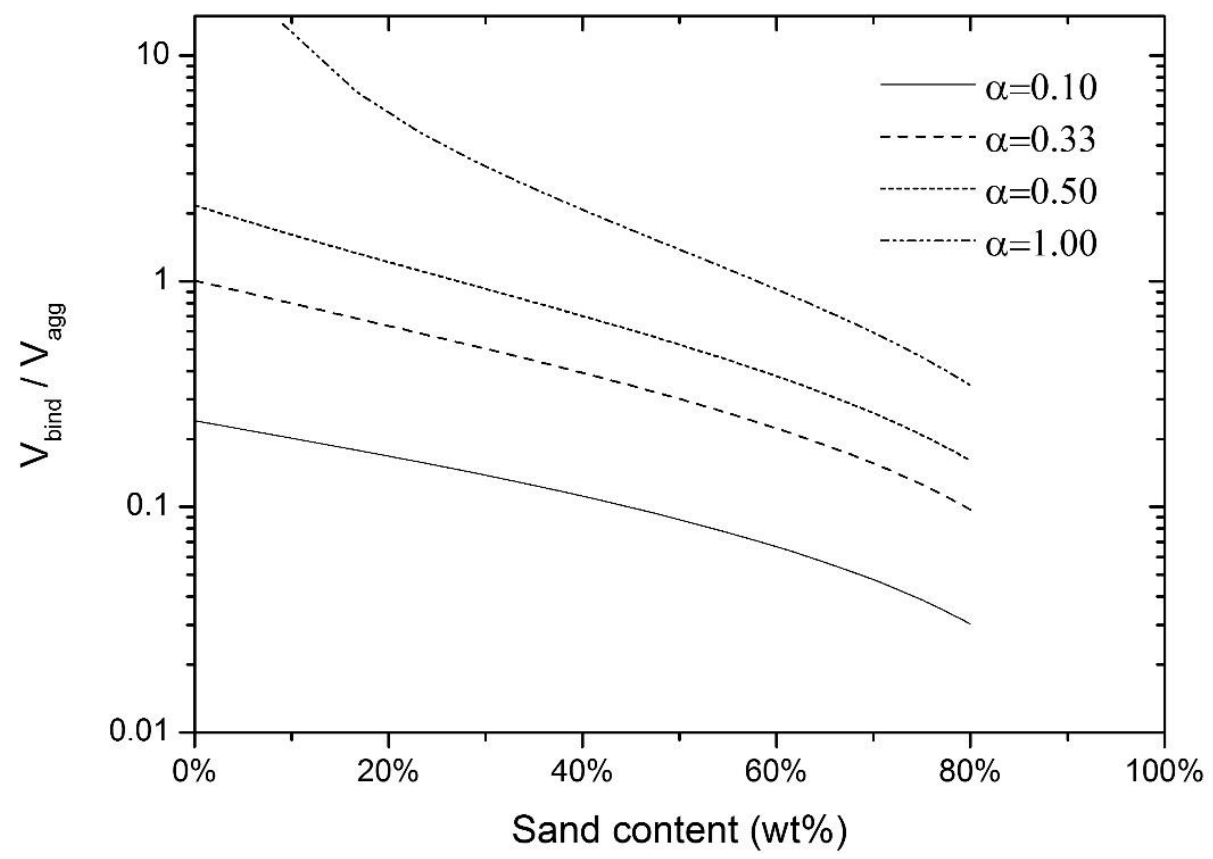

Fig. 8. Ratio of binder, $\mathrm{V}_{\text {bind }}$, to aggregate volume, $\mathrm{V}_{\mathrm{agg}}$, as a function of the sand content and different extents of reaction. 